\title{
Comparative Study of Inotropic Effects of Catechol- amines on Blood-perfused Canine Papillary Muscle
}

\author{
Masao Endoh, Tomohiko Kimura and Koroku Hashimoto \\ Department of Pharmacology, Tohoku University School of \\ Medicine, Sendai
}

Endoh, M., Kimura, T. and Hashimoto, K. Comparative Study of Inotropic Effects of Catecholamines on Blood-perfused Canine Papillary Muscle. Tohoku J. exp. Med., 1972, 106 (2), 165-173 - The relative inotropic potencies of isoproterenol, norepinephrine, epinephrine and phenylephrine were compared in the blood-perfused canine papillary muscle preparation. The muscle was perfused at a constant pressure of $100 \mathrm{~mm} \mathrm{Hg}$ at $38-39^{\circ} \mathrm{C}$ with arterial blood from a donor animal. The isometric tension developed by the papillary muscle and the positive inotropic effect of catecholamines were a function of the stimulus frequency. The potencies of the inotropic effect of catecholamines were compared at various stimulus frequencies from 90 to $240 / \mathrm{min}$. Isoproterenol, norepinephrine and epinephrine, 0.001 to $0.1 \mu \mathrm{g}$. caused reproducible positive inotropic effects lasting for from 2 to $5 \mathrm{~min}$, when the perfused blood flow of the muscles was from 3 to $5 \mathrm{ml} / \mathrm{min}$. Phenylephrine, 0.01 to $1 \mu \mathrm{g}$, caused no inotropic effect. The order of potencies of inotropic effect of each amine was isoproterenol $>$ norepinephrine $>$ epinephrine $\gg$ phenylephrine. The dose ratio required to produce $100 \%$ increase in isometric tension was $\mathrm{IS}: \mathrm{NE}: \mathrm{EP}=1: 3: 6$ at stimulus frequencies of 90 and $120 / \mathrm{min}$. The ratio of the percentage increase produced by $0.03 \mu \mathrm{g}$ of each agent was roughly $\mathrm{IS}: \mathrm{NE}: \mathrm{EP}=3: 2: 1$ and $5: 3: 1$ at 90 and $120 / \mathrm{min}$, respectively. Norepinephrine produced a distinctly stronger positive inotropic effect than did epinephrine and the differences between these amines were statistically significant. - catecholamines; inotropic effect; papillary muscle

The inotropic potencies of catecholamines, naturally occurring and synthetic, have been determined in various preparations of mammalian ventricular muscle, i.e., isolated papillary muscles (Garb 1950, Lee and $\mathrm{Yu} 1964$ ), heart-lung preparation (Crismon and Tainter 1938, Fawaz and Tutunji 1960) and hearts in situ (Goldberg et al. 1953, Cotten and Pincus 1955, Moran 1966). While isoproterenol was found to be the most potent catecholamine (Lands and Howard 1952, Moran 1966), differences in potencies between epinephrine and norepinephrine occur among various species of animals. In the canine heart it is reported that norepinephrine exhibits approximately an equal or slightly stronger inotropic effect than epinephrine. But there are considerable variations when assessed in different preparations, thus quantitative differences are hardly comparable. Difference in the experimental conditions may also influence the results. In the isolated papillary muscle hypoxia may exist because coronary vessels are not perfused (Blinks and Koch-Weser 1963). Such hypoxic conditions are not favorable for the assessment of the inotropic

Received for publication, June 24, 1971. 
potency of catecholamines. On the other hand, various factors such as the venous return, stroke volume, peripheral resistance, and above all heart rate, may modify the precise comparison of the inotropic effoct of these drugs in situ. Recently we developed the blood-perfused canine papillary muscle preparation by a crosscirculation technique (Endoh and Hashimoto 1970, a, b; Endoh et al. 1970). In the present study, these various difficulties were avoided using this preparation for a comparison of the inotropic potencies of norepinephrine, epinephrine, isoproterenol and phenylephrine.

\section{METHODS}

Sixteen mongrel dogs, weighing 7 to $10 \mathrm{~kg}$, were anesthetized with ether. After heparinization $(1,000 \mathrm{U} / \mathrm{kg}, i . v$.$) , the heart was excised and plunged into cold Tyrode's$ solution at 3 to $6{ }^{\circ} \mathrm{C}$, equilibrated with $95 \% \mathrm{O}_{2}$ and $5 \% \mathrm{CO}_{2}$. The anterior septal artery was dissected and cannulated. All branches except the arteries to the anterior papillary muscle were ligated. Indigo carmine, $0.4 \%$ in saline solution, was used to make the papillary muscle arteries visible. The isolated muscle was perfused through the septal artery with arterial blood of a donor dog by the aid of a Sigmamotor pump. A pneumatic resistance was placed in parallel with the perfusion system so that a constant perfusion pressure at $100 \mathrm{~mm} \mathrm{Hg}$ was maintained. The papillary muscle was maintained at a constant temperature of $38-39^{\circ} \mathrm{C}$ in a bell shaped glass container which was warmed by circulating warm water pumped from a water bath. The tendinous end of the papillary muscle was connected to a force displacement transducer (Grass FT 03) by a fine silk thread and stretched with a weight of about $1 \mathrm{~g}$. The perfusing blood flow was measured from time to time with a graduated cylinder and ranged from 3 to $5 \mathrm{ml} / \mathrm{min}$. The perfused blood was returned to the donor through the jugular vein. The donor dogs were anesthetized with morphine, $10 \mathrm{mg} / \mathrm{kg}$, s.c. and urethan, $1 \mathrm{~g} / \mathrm{kg}$, s.c.. Sodium heparin, $500 \mathrm{U} / \mathrm{kg}$, was given at the beginning of the experiment and $200 \mathrm{U} / \mathrm{kg}$ were added at 1 hour intervals. The muscle was electrically driven by an electronic stimulator (Nihon Kohden MSE-3) through bipolar platinum electrodes with stimulus pulses of 0.5 to 1.5 volts (approximately twice threshold), $5 \mathrm{msec}$ duration and $120 / \mathrm{min}$. It has been ascertained that no electro-release of autonomic transmitters (Blinks 1966) occurred under these conditions (Endoh and Hashimoto 1970, b). Isometric contractions were recorded on an ink-writing oscillograph (Nihon Kohden WI-130) through a force displacement transducer, a carrier preamplifier (Nihon Kohden RP-3) and a main amplifier (Nihon Kohden AD 222). The drug solutions, 0.01 to $0.03 \mathrm{ml}$, were injected at $10 \cdot \mathrm{min}$ intervals into the rubber tube close to its connection with the shank of the polyethylene cannula, in a period of 4 seconds by a microinjector (Jintan Terumo Co.). The details of the experimental setup were described in a previous paper (Endoh and Hashimoto 1970, b). The drugs used in these experiments were $l$-norepinephrine (Fluka AG), l-epinephrine (Merck AG), $l$ isoproterenol (Kaken Kagaku) and phenylephrine hydrochloride (Kowa). All doses given are expressed in terms of the base. The desired concentration was obtained by dilution of the stock solution with saline. An injection of $0.03 \mathrm{ml}$ of saline in 4 seconds had no effect on the contractile force. Statistical analysis of the results was performed using Student's $t$ test and statistical significance of the differences was expressed as $P$ values.

\section{RESUlts}

\section{1) Frequency-force relationship and positive inotropic effect of sympathomimetic amines}

The contractile tension of the blood-perfused canine papillary muscle was markedly influenced by stimulus frequency of the muscle (Fig. 1) as described in 


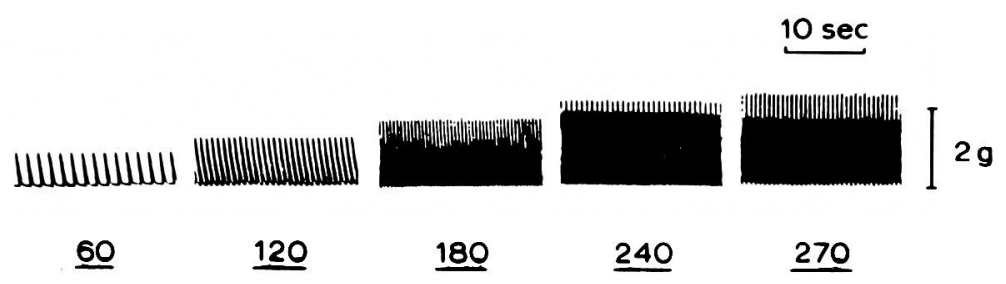

Stimulus frequency ( $/ \mathrm{min}$ )

Exp. No. 23

Fig. 1. Effect of changes of stimulus frequency on the isometric contractile tension of the blood-perfused canine papillary muscle.

the previous paper (Endoh and Hashimoto 1970, b). When the stimulus frequency was increased from 60 to 120,240 and $270 / \mathrm{min}$, keeping the stimulus pulse duration and voltage constant at about twice threshold, isometric contractile tension was augmented. A slight alternation of tension developed at $240 / \mathrm{min}$, which became marked when the frequency was $270 / \mathrm{min}$. The average effect of the stimulus frequency on the contractile tension in 7 papillary muscles is shown in Table 1.

TABLE 1. Effect of stimulation frequency on the isometric contractile tension of the blood-perfused caniinc pxpillary muscle

\begin{tabular}{|c|c|c|c|c|c|c|}
\hline & \multicolumn{6}{|c|}{ Stimulus frequency (/min) } \\
\hline & 60 & 90 & 120 & $180^{b}$ & $240^{b}$ & $270^{b}$ \\
\hline \multirow{2}{*}{$\begin{array}{l}\text { Isometric contractile } \\
\text { tension }(\mathrm{g})\end{array}$} & 1. $7^{\mathrm{a}}$ & 1.9 & 2. 2 & 2.7 & 3.1 & 3.2 \\
\hline & 0.1 & 0.1 & 0.1 & 0.2 & 0.3 & 0.3 \\
\hline
\end{tabular}

a Isometric contractile tension in gram, each value is mean of 7 muscles $(n=7)$

$b$ Values of the isometric tension are expressed as mean of paired large and small contractions of pulsus alternans over the frequencies of $180 / \mathrm{min}$.

This augmentation of contractile tension by high frequency stimulation is not directly related to an electro-release of autonomic transmitters (Endoh and Hashimoto 1970 b) which may occur with strong electrical stimulation as reported in the previous paper (Endoh and Hashimoto 1970, a). As the contractile performance of the ventricular myocardium is a function of the stimulus frequency, it is to be expected that the inotropic effect of catecholamines will be modified by changes in rate. Therefore the inotropic effect of sympathomimetic amines was compared at various frequencies of from 90 to $140 / \mathrm{min}$ as shown in Figs. 2 and 3 . Fig. 2 illustrates the positive inotropic effect of $0.01 \mu \mathrm{g}$ of epinephrine, norepinephrine, and isoproterenol at stimulus frequencies of 120,150 and $180 / \mathrm{min}$ in a typical experiment. Percentage increase of the contractile tension by intra-arterial administration of $0.01 \mu \mathrm{g}$ of four sympathomimetic amines at different stimulus frequencies in a typical experiment is shown graphically in Fig. 3. When the stimulus frequency is raised from 90 to $120-150 / \mathrm{min}$, the positive inotropic effect of each amine 


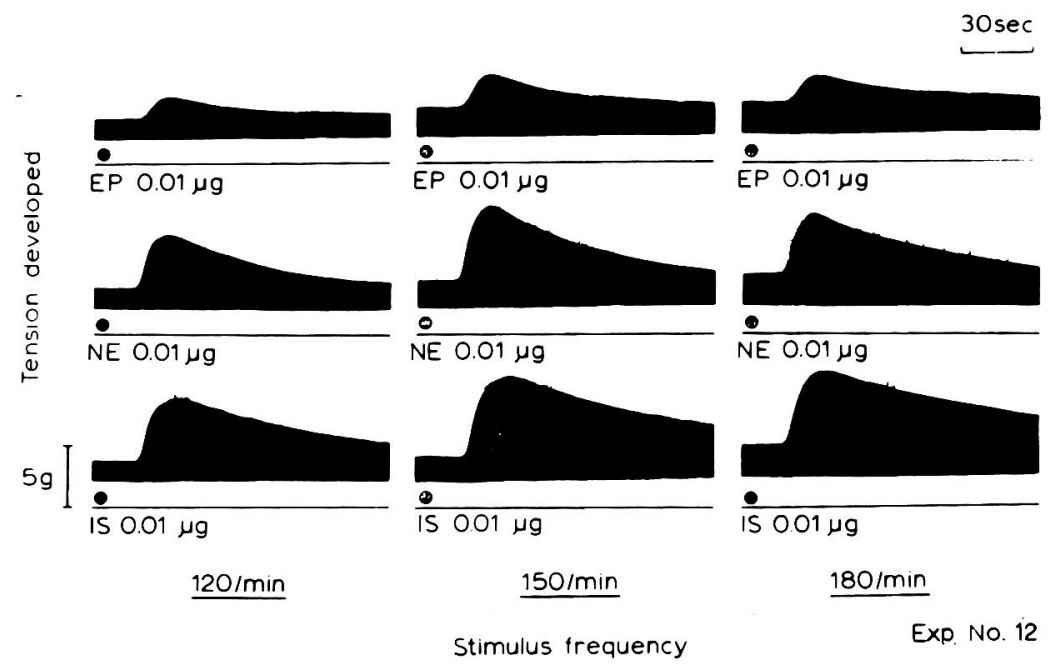

Fig. 2. Positive inotropic effects of catecholamines_on the muscle at stimulus frequencies of $120, \$ 150$ and 180/min. $\mathbf{E P}$ : [epinephrine. NE: norepinephrine. IS: isoproterenol.

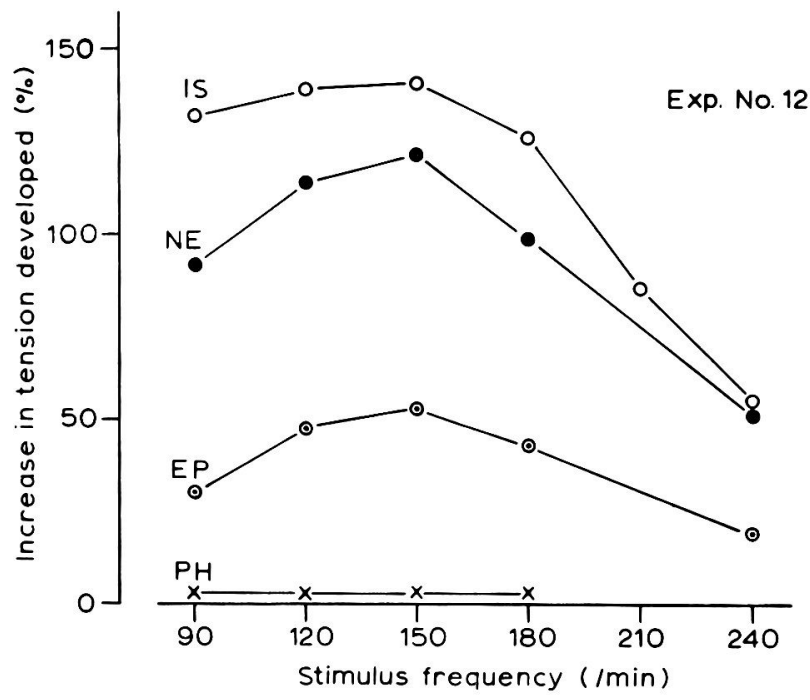

Fig. 3. Positive inotropic effects of $0.01 \mu \mathrm{g}$ of four sympathomimetic amines at various stimulus frequencies of from 90 to $240 / \mathrm{min}$. O IS: isoproterenol. NE: norepinephrine. $\odot$ EP: epinephrine. $\times$ PH: phenylephrine.

increased gradually in spite of the increased control contractile tension resulting from high frequency stimulation. Further increase of stimulus frequency beyond $150 /$ min reduced the positive inotropic effect of the catecholamines which was most prominent at frequencies of 120 to $150 / \mathrm{min}$. 
2) Comparison of the positive inotropic effect of isoproterenol, norepinephrine, epinephrine and phenylephrine at stimulus frequencies of 90 and $120 / \mathrm{min}$

Since the positive inotropic effect of catecholamines was influenced by stimulus frequency as described above, the inotropic effect of these amines was compared at two different stimulus frequencies of 90 and 120/min corresponding approximately to the heart rate in the intact $\mathrm{dog}$, around which the positive inotropic effects were most pronounced. The percentage increase of contractile tension by 0.01 to $0.1 \mu \mathrm{g}$ of each agent is shown in Fig. 4. Isoproterenol had the greatest positive inotropic effect and the longest duration of action. $0.03 \mu \mathrm{g}$ of isoproterenol produced a percentage increase of $150 \pm 19$ (mean \pm s.E.; $n=6$ ) at $90 / \mathrm{min}$ and $233 \pm 18$ at $120 / \min (n=5)$. This dose of isoproterenol was found to be the maximum dose permissible for repetitive administration in the present study, because extrasystolic contractions were evoked and the contractile force under the basal condition of stimulation was diminished and not recovered within 30 min. The duration of action of $0.03 \mu \mathrm{g}$ isoproterenol was 4 to $5 \mathrm{~min}$ and the half time of action was $53 \pm 5$ sec $(n=8)$. Isoproterenol sometimes produced extrasystolic contractions, which often disturbed the measurement of the positive inotropic effect. Norepinephrine produced a more prominent potitive inotropic effect than
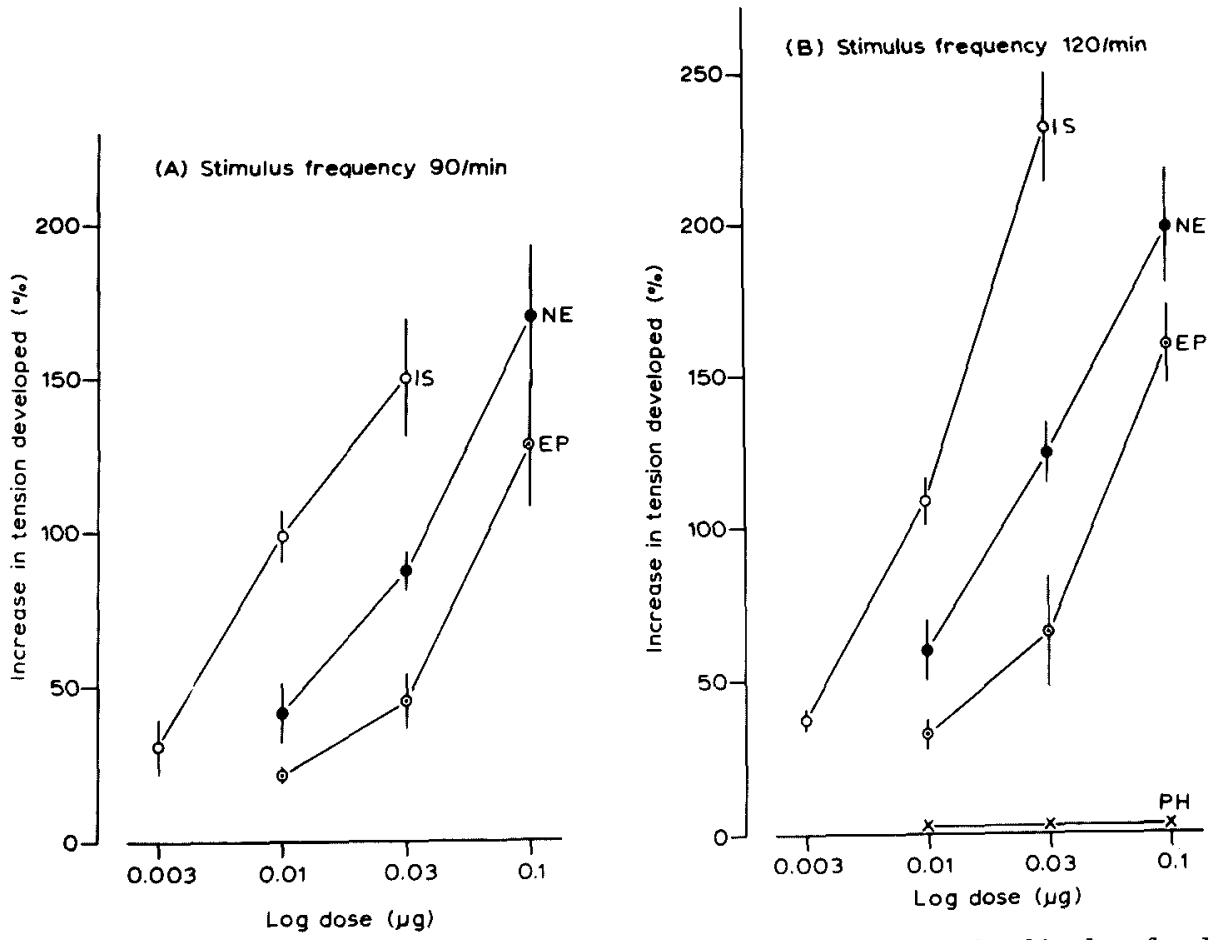

Fig. 4. Positive inotropic effects of sympathomimetic amines on the blood-perfused canine papillary muscle at stimulus frequencies of $90 / \mathrm{min}$ (A) and $120 / \mathrm{min}$ (B). NE: norepinephrine. $\odot$ EP: epinephrine. $\bigcirc$ IS: isoproterenol. $\times \mathrm{PH}:$ phenylephrine. 
epinephrine. Norepinephrine in a dose of $0.1 \mu \mathrm{g}$ caused a percentage increase of $170 \pm 23(n=6)$ at $90 / \mathrm{min}$ and $200 \pm 19(n=6)$ at $120 / \mathrm{min}$. The effect of norepinephrine lasted for from 2 to $3 \mathrm{~min}$ and the half time of action was $44 \pm 6$ sec. Epinephrine in $0.1 \mu \mathrm{g}$ doses caused a percentage increase of $128 \pm 20 \quad(n=6)$ at $90 / \mathrm{min}$ and $161 \pm 13(\mathrm{n}=6)$ at $120 / \mathrm{min}$. The duration of action of epinephrine was 1.5 to $2.5 \mathrm{~min}$ and the half time of action was $35 \pm 6 \mathrm{sec}(\mathrm{n}=8)$. Phenylephrine, 0.01 to $1 \mu \mathrm{g}$, produced no inotropic effect at any of the stimulus frequencies investigated in the present study.

\section{3) Consideration of the potency of the inotropic effect of catecholamines}

The inotropic potencies of catecholamines have been compared by others at various heart rates, controlled or not controlled, in various ways according to the type of preparation used. In the present study the positive inotropic effects of catecholamines were compared in two ways: a) the dose ratio required to produce the same percentage increase of contractile tension and $b$ ) the ratio of the percentage increase of contractile tension produced by equivalent doses of the agents at stimulus frequencies of 90 and $120 / \mathrm{min}$.

TABLE 2. Ratio of percentage increase of contractile tension produced by norepinephrine and isoproterenol to epinephrine control (100)

\begin{tabular}{|c|c|c|c|}
\hline & & \multicolumn{2}{|c|}{ Ratio to epinephrine control (100) } \\
\hline & & \multicolumn{2}{|c|}{ Stimulus frequency } \\
\hline & & $90 / \mathrm{min}$ & $120 / \mathrm{min}$ \\
\hline \multirow{5}{*}{$\begin{array}{c}\text { Norepinephrine } \\
(\mu \mathrm{g})\end{array}$} & 0.01 & $246 \pm 36(6)$ & $280 \pm 47(6)$ \\
\hline & & $\mathrm{p}^{a}<0.02$ & $\mathrm{p}<0.05$ \\
\hline & 0.03 & $212 \pm 31(7)$ & $254 \pm 55(5)$ \\
\hline & 0.1 & $178 \pm 1 \quad(5)$ & $128+6(5)$ \\
\hline & & $\mathrm{p}<0.01$ & $\mathrm{p}<0.01$ \\
\hline \multirow{2}{*}{$\begin{array}{c}\text { Isoproterenol } \\
(\mu \mathrm{g})\end{array}$} & 0.01 & $506 \pm 102(5)$ & $439 \pm 137(6)$ \\
\hline & 0.03 & $334 \pm 52(6)$ & $487 \pm 128(5)$ \\
\hline
\end{tabular}

a Differences between epinephrine and norepinephrine.

a) The dose ratio producing $100 \%$ increase of contractile tension was calculated from the dose-response curves shown in Fig. 4, since these are almost parallel for the catecholamines tested. The dose ratios resulting in $100 \%$ increase of contractile tension were IS: NE: $\mathrm{EP}=1: 3.6: 6.8$ at $90 / \mathrm{min}$ and $1: 2.3: 5.2$ at $120 /$ min, or approximately $1: 3: 6$.

b) The increase of the contractile tension resulting from isoproterenol and norepinephrine was expressed as a percentage of the epinephrine control in the same papillary muscle because responses varied considerably from one preparation to another depending on the blood flow. The data are given in Table 2. The ratios of the percentage increase produced by $0.03 \mu \mathrm{g}$ of each agent at which 
dose-response curves were relatively parallel were $\mathrm{EP}: \mathrm{NE}: \mathrm{IS}=1: 2.1: 3.3$ at $90 / \mathrm{min}$ and $1: 2.5: 4.9$ at $120 / \mathrm{min}$.

Differences in inotropic potency between epinephrine and norepinephrine were compared using Student's $t$-test. $P$ values are presented in Table 2, which indicate the statistical significance of the difference between epinephrine and norepinephrine at all doses administered.

\section{Discussion}

Blood-perfused canine papillary muscles used in the present study responded to electrical stimulation of $120 / \mathrm{min}$ at $38-39^{\circ} \mathrm{C}$ for over 10 hours without any deterioration of contractile tension, while that of the muscles in physiological solution decreased gradually over many hours under conditions of $38^{\circ} \mathrm{C}$ and stimulus frequency of $60 / \mathrm{min}$ (Garb 1950, Lee and $\mathrm{Yu}$ 1964). Thus, the blood-perfused canine papillary muslce is probably free from hypoxia in contrast to the preparation in physiological saline solution. Furthermore, the metabolic state of the blood-perfused papillary muscle should be more closely related to that in the mammalian ventricle in vivo. Lee and $\mathrm{Yu}$ (1964) suggested that the metabolic state of the muscle should be taken into consideration whenever the influence of sympathomimetic amines on the mechanical efficiency of the heart is investigated.

The contractile tension of the ventricular muscle is a function of heart rate (Fig. 1) and the positive inotropic effect of catecholamines is influenced by stimulus frequency (Fig. 3), therefore the heart rate must be considered when the inotropic effect of catecholamines are compared. Changes in heart rate together with changes in venous return, stroke volume and peripheral resistance might modify the true inotropic effect of catecholamines. Heart rate has not been controlled ordinarily in the in situ experiments (Crismon and Tainter 1938, Lands and Howard 1952, Goldberg et al. 1953, Cotten and Pincus 1955, Fawaz and Tutunji 1960).

It has been reported that isoproterenol exhibited the most potent inotropic effect among catecholamines in the rabbit (Lands and Howard 1952) and in the dog (Moran 1966). Moran (1966), using anesthetized, vagotomized, open-chest dogs, showed that isoproterenol is 4 to 5 times more potent than epinephrine and norepinephrine. In the present study isoproterenol is 3 to 5 times more potent than norepinephrine and 5 to 7 times more potent than epinephrine based on the dose required to produce a $100 \%$ increase in contractile tension. Thus the present data on isoproterenol agree with those of Moran in the canine heart in vivo.

It has been reported that norepinephrine and epinephrine exhibit almost equal positive inotropic effects in the cat (Garb 1950, Lee and Yu 1964) and dog (Cotten and Pincus 1955, Moran 1966) heart. Cotten and Pincus (1955) have shown that the positive inotropic effect of $l$-epinephrine and $l$-norepinephrine, as measured directly with a strain gauge in the in situ canine heart, to be qualitatively and quantitatively similar over a wide dosage range. But they did not control the heart rate and it is probable that this factor together with others described 
previously may modify the true inotropic effect of these amines. Garb (1950), and Lee and $\mathrm{Yu}$ (1964), using isolated cat papillary muscle, observed that increases in contractility with norepinephrine were slightly greater than those seen with epinephrine. However, there was considerable variation in the degree of the increase, so that quantitative relationships between drugs could not be established. In the blood-perfused canine papillary muscle norepinephrine had about twice the inotropic potency as did epinephrine, the difference being statistically significant at all doses administered at various stimulus frequencies (Table 2). Crismon and Tainter (1938) reported that norepinephrine exhibited twice the potency of epinephrine in the cat heart-lung preparation. The present results are consistent with those of Crismon and Tainter (1938) and indicate that norepinephrine exhibits a greater inotropic effect than does epinephrine in the controlled and blood-perfused state in cat and canine hearts. The duration of action of these agents was 2 to $5 \mathrm{~min}$ and was consistent with the results of Goldbert et al. (1953) working with the canine heart in situ.

The positive inotropic effect of catecholamines increased gradually as the stimulus frequency was raised from 90 to $150 / \mathrm{min}$ and was most prominent at frequencies of from 120 to $150 / \mathrm{min}$. Further increase of frequency reduced the positive inotropic effect. Koch-Weser, Berlin and Blinks (1963) have suggested that the positive inotropic effect of catecholamines was caused by the accumulation of "positive inotropic effect of activation" related to the amount produced per beat, and thus the higher the frequency, the stronger is the positive inotropic effect (Koch-Weser and Blinks, 1963). In the present study pulsus alternans always developed at frequencies between 180 and $240 / \mathrm{min}$ and the positive inotropic effect of catecholamines decreased remarkably at these frequencies. Pulsus alternans also has been observed at these frequencies in the canine heart in situ (Gilbert et al. 1965). This suggests that the frequency of 180 to $240 / \mathrm{min}$ is the physiological upper limit of the heart rate which the canine ventricular muscle can follow and above which the drug cannot act effectively even in the blood-perfused ventricular muscle. Relative oxygen deficiency may occur at high stimulus frequencies, since the blood supply will be restricted by abbreviation of the diastolic pause, more oxygen will be required than at low frequencies, and further increase of oxygen consumption is caused by catecholamines. For these reasons the papillary muscle response to catecholamines may be limited.

\section{Conclusions}

Inotropic potencies of isoproterenol, norepinephrine, epinephrine and phenylephrine on canine ventricle were compared in the physiological and controlled conditions using the blood-perfused papillary muscle. The order of potencies was isoproterenol $>$ norepinephrine $>$ epinephriue $\gg$ phenylephrine $(5-6: 2-3: 1$ :none). Inotropic effects of each amine were stimulus frequency dependent. 


\section{Acknowledgment}

We express our thanks to Prof. McKeen Cattell, Cornell University Medical College, for reviewing the manuscript and Miss R. Horiuchi for typewriting it.

This study was partly supported by the Pharmacological Research Foundation, Inc. and Sankyo Central Laboratories.

\section{References}

1) Blinks, J.R. (1966) Field stimulation as a means of effecting the graded release of autonomic transmitters in isolated heart muscle. J. Pharmacol. exp. Ther., 151, $221-235$.

2) Blinks, J.R. \& Koch-Weser, J. (1963) Physical factors in the analysis of the actions of drugs on myocardial contractility. Pharmacol. Rev., 15, 531-599.

3) Cotten, M. deV. \& Pincus, S. (1955) Comparative effects of a wide range of doses of $l$-epinephrine and of $l$-norepinephrine on the contractile force of the heart in situ. $J$. Pharmacol. exp. Ther., 114, 110-118.

4) Crismon, J.M. \& Tainter, M.L. (1938) Action of sympathomimetic amines on the heart-lung preparation. $J$. Pharmacol. exp. Ther., 64, 190-208.

5) Endoh, M. \& Hashimoto, K. (1970a) Pharmacological evidence of autonomic nerve activities in canine papillary muscle. Amer. J. Physiol., 218, 1459-1463.

6) Endoh, M. \& Hashimoto, K. (1970b) Frequency-force relationship in the bloodperfused canine papillary muscle preparation. Jap. J. Physiol., 20, 320-331.

7) Endoh, M., Tamura, K. \& Hashimoto, K. (1970) Negative and positive inotropic responses of the blood-perfused canine papillary muscle to acetylcholine. $J$. Pharmacol. exp. Ther., 175, 377-387.

8) Fawaz, G. \& Tutunji, B. (1960) The effects of adrenaline and noradrenaline on the metabolism and performance of the isolated dog heart. Brit. J. Pharmacol, 15, 389-395.

9) Garb, S. (1950) Inotropic action of epinephrine, nor-epinephrine, and N-isopropylnorepinephrine on heart muscle. Proc. Soc. exp. Biol. Med., 73, 134-135.

10) Gilbert, J.L., Janse, M.J., Lu, H.H., Pinkston, J.O. \& Brooks, C. McC. (1965) Production and abolition of alternation in mechanical action of the ventricle. Amer. $J$. Physiol., 209, 945-950.

11) Goldberg, L.I., Cotten, M. deV., Darby, T.D. \& Howell, E.V. (1953) Comparative heart contractile force effects of equipressor doses of several sympathomimetic amines. J. Pharmacol. exp. Ther., 108, 177-185.

12) Koch-Weser, J., Berlin, C.M., Jr. \& Blinks, J.R. (1963) Effects of acetylstrophanthidin, levarterenol and carbachol on the interval-strength relationship of heart muscle. Proc. 2nd Int. Pharmacol. Meeting, 5, 63-72.

13) Koch-Weser, J. \& Blinks, J.R. (1963) The influence of the interval between beats on myocardial contractility. Pharmacol. Rev., 15, 601-652.

14) Lands, A.M. \& Howard, J.W. (1952) A comparative study of the effects of $l$-arterenol, epinephrine and isopropylarterenol on the heart. J. Pharmacol. exp. Ther., 106, 6576.

15) Lee, K.S. \& Yu, D.H. (1964) Effects of epinephrines on metabolism and contraction of cat papillary muscle. Amer. J. Physiol., 206, 525-530.

16) Moran, N.C. (1966) Neurohumoral agents - A pharmacological analysis of the actions of catecholamines upon the heart. In: The Myocardial Cell: Structure, Function, and Modification by Cardiac Drugs, edited by S.A. Briller \& H.L. Conn, Jr., University of Pennsylvania Press, Philadelphia, pp. 331-354. 